Abstract AB0725 - Table 2

\begin{tabular}{|c|c|c|c|c|c|}
\hline & $\begin{array}{c}\text { Dysphagia } \\
\text { (mild-moderate) } \\
30 / 48\end{array}$ & $\begin{array}{c}\text { Dysphagia } \\
\text { (severe) } \\
18 / 48\end{array}$ & $p$ & OR & $\begin{array}{c}\text { IC } \\
95 \%\end{array}$ \\
\hline $\begin{array}{l}\text { Weakness of respiratory } \\
\text { muscles }\end{array}$ & $4 / 30$ & $9 / 18$ & 0005 & 6,5 & $\begin{array}{c}1,6- \\
26\end{array}$ \\
\hline Weak neck muscles & $9 / 30$ & $13 / 18$ & 0004 & 6 & $\begin{array}{c}1,6- \\
22\end{array}$ \\
\hline Glucocorticoid pulses & $5 / 28$ & $13 / 18$ & 0,0002 & 12 & $\begin{array}{c}2,9- \\
49\end{array}$ \\
\hline Gammaglobulin & $3 / 30$ & 10/18 & 0,0005 & 10 & $\begin{array}{c}2,4- \\
51\end{array}$ \\
\hline Intensive therapy unit & $1 / 30$ & $7 / 18$ & 0,0013 & 18 & 2-167 \\
\hline $\begin{array}{l}\text { Mechanical respiratory } \\
\text { assistance }\end{array}$ & $1 / 30$ & $6 / 18$ & 0004 & 14,50 & $\begin{array}{l}1,5- \\
133\end{array}$ \\
\hline Grave Infections & $5 / 27$ & $10 / 18$ & 0009 & 5,50 & $\begin{array}{c}1,4- \\
21\end{array}$ \\
\hline Death & $3 / 30$ & $13 / 18$ & $<0.001$ & 23,5 & $\begin{array}{r}4,8- \\
113 \\
\end{array}$ \\
\hline
\end{tabular}

Conclusions: Fifty-three percent of patients with MII had dysphagia at some point during their evolution. Severe dysphagia was associated with parameters of disease severity, poor prognosis and increased mortality.

Disclosure of Interest: None declared

DOI: 10.1136/annrheumdis-2018-eular.5367

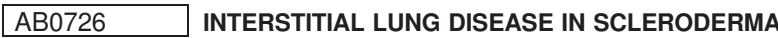 PATIENTS - A PORTUGUESE PORTRAIT}

A.C. Duarte $^{1}$, A. Cordeiro ${ }^{1}$, T. Santiago ${ }^{2,3}$, M.J. Salvador ${ }^{2,3}$, M.J. Santos ${ }^{1}$. ${ }^{1}$ Rheumatology, Hospital Garcia de Orta, Almada: ${ }^{2}$ Rheumatology, Centro Hospitalar e Universitário de Coimbra; ${ }^{3}$ Faculty of Medicine, University of Coimbra, Coimbra, Portugal

Background: Systemic sclerosis (SSc) is characterised by inflammation and fibrosis of skin and internal organs. Lung involvement, particularly interstitial lung disease (ILD), is a major cause of morbidity and a leading cause of SSc-related mortality.

Objectives: To characterise SSc patients (pts) with ILD and identify possible predictors for its development.

Methods: A multicenter prospective cohort study using the Rheumatic Diseases Portuguese Register/Scleroderma database was performed. All patients fulfilled ACR/EULAR 2013 classification criteria for SSc. Demographic and clinical data until 15th January 2018 were collected as well as pulmonary function tests (PFTs), including diffusing capacity of carbon monoxide (DLCO). ILD was defined by fibrosis in chest x-ray and/or high-resolution computed tomography (HRCT) scan. Disease progression was defined by an increase from baseline in the area of involved parenchyma and/or development of honeycombing in pts with previous ground glass imaging and/or reduction of more than $15 \%$ in DLCO or $10 \%$ in forced vital capacity in pts with stablished ILD. We performed a descriptive analysis of SSc cohort. Logistic regression analysis was used to identify variables independently associated with ILD.

Results: A total of 146 pts were included, $88.4 \%$ female, with a mean age of 61.5 \pm 14.4 years (yrs) and mean disease duration of $14.3 \pm 11.3$ years. Limited cutaneous SSc (ISSc) was present in $66.4 \%$, diffuse cutaneous SSc (dSSc) in $24 \%$, overlap syndrome in $6.8 \%$ and very early diagnosis SSc in $1.4 \%$ (information missing in 2pts).

In our cohort, 42 pts (28.8\%) presented ILD after $17.5 \pm 14.1$ years of disease duration, $83.5 \%$ of them were female; $45.2 \%$ had dSSc and $42.9 \%$ ISSc. Anti-Scl70 antibody occurred in 23 pts, anticentromere antibody (ACA) in 8, anti-Pm/Scl in 2, anti-RNA polymerase I in 2, anti-RNA polymerase III in 1 and anti-U3RNP in 1. Ten pts had current/previous smoking habits. Nailfold capillaroscopy (NCP) was available in 23 out of 42 pts and 21 had a SSc pattern (5 early, 6 active and 10 late). Table 1 shows differences between pts with and without ILD.

In multivariate analysis, anti-Scl70 (OR:3.7 95\% Cl 1.3-10.5) and current/previous digital ulcers (OR:2.2 95\% Cl 1.9-5.3) were associated with ILD development. ACA had a protective effect (OR:0.3 95\% $\mathrm{Cl} 0.1-0.8$ ).

Mycophenolate mofetil was used in $11 \mathrm{pts}$, with 5 of them having previous treatment with cyclophosphamide (CYC; 4 as induction drug). Four pts received azathioprine, half of them as maintenance therapy after induction with CYC. Two pts received rituximab and 1 nintedanib.

During follow-up, disease progression occurred in 17 pts (40.1\%), 3 of them under immunosuppression.

Death occurred in 7 pts with ILD, 5 of them with direct relation to lung disease, 14.4 years after the diagnosis.

Table 1 Differences between patients with and without ILD (total=146)
Conclusions: This was the first multicentre Portuguese study about ILD in SSc. In our cohort, ILD occurred in about $30 \%$ of the pts and was associated with a mortality rate of $3.4 \%$.

Our results confirm that some variables are associated with pulmonary disease development, and thus its identification may help the clinician to detect pts with a higher risk of early ILD.

Disclosure of Interest: None declared

DOI: 10.1136/annrheumdis-2018-eular.7230

\section{AB0727 ANTIBODY PROFILE AND SYSTEMIC SCLEROSIS CLINICAL FEATURES - MYTH OR REALITY?}

A.C. Duarte, A. Cordeiro, M.J. Santos, J. Canas da Silva. Rheumatology, Hospital Garcia de Orta, Almada, Portugal

Background: Antinuclear antibodies(ANA) occur in $80 \%-98 \%$ of systemic sclerosis(SSc) patients (pts), with different specificities. Anticentromere antibody (ACA), antitopoisomerase I(anti-Scl70) and anti-RNA polymerase III are the commonest and are included in the new SSC ACR/EULAR classification criteria. According to literature, ANA specificities are associated with clinical features of the disease.

Objectives: Evaluate the relationship between antibody profile and clinical manifestations in a cohort of SSc pts.

Methods: We conducted a retrospective analysis of SSc pts followed in ou department. Demographic data, disease duration, ANA specificities and clinical manifestations were collected. Mann-Whitney $U$ test and Chi-square were used for comparisons between pts who tested positive or negative for different ANA specificities.

Results: In total, 117 pts were included, $91.5 \%$ female with mean age of 60.7 \pm 15.2 years and mean disease duration of $11.9 \pm 10.7$ years. Seventy-five pts $(64.1 \%)$ had limited cutaneous SSc(IcSSC), 26 (22.2\%) diffuse cutaneous SSc (dcSSc), $8(6.8 \%)$ very early diagnosis SSc, $7(6 \%)$ overlap syndromes and 1 (0.9\%) SSc sine scleroderma. Most (92.3\%) were ANA positive, with $53.8 \%$ hav ing ACA, 26.5\% anti-Scl70, 3.4\% anti-U3 RNP, 2.6\% anti-U1 RNP, 1.7\% anti-PM Scl and $0.9 \%$ anti-RNA polymerase III and $0.9 \%$ anti-Th/To.

Positivity for ACA was significantly associated with female gender (OR: 1.18 95\% Cl 1.04-1.34) and IcSSc phenotype (OR: 9.43 95\% Cl 3.86-23.03). ACA was also associated with older age at disease onset $(p=0.008)$. Vascular involvement, defined by current/previous digital ulcers and/or telangiectasias, was also more prevalent in this group (OR: $5.5995 \% \mathrm{Cl}$ 2.47-12.66). Pulmonary arterial hypertension (group $1 \mathrm{ERS} / \mathrm{ECS}^{2013}$ classification) was present in $6.3 \%$ of pts with ACA. Oesophageal involvement was the second commonest manifestation and occurred in $57.1 \%$ of pts with ACA, although this association was not statistically significant. ACA seemed to have a protective effect for interstitial lung disease (ILD) (OR: 0.027 95\% Cl 0.004-0.213).

Anti-Scl70 positivity was associated with dcSSc phenotype (OR: $9.2995 \% \mathrm{Cl}$ 3.26-26.5) and ILD (OR: 10.39 95\% Cl 3.86-27.92).

From the 4 pts with anti-U3 RNP, 3 had dcSSC subtype. The only patient with renal manifestations was anti-U3 RNP positive and had rapidly progressive cutaneous involvement.

Abstract AB0727 - Table 1. Clinical features according to auto-antibody positivity

\begin{tabular}{|l|l|l|l|l|l|l|l|}
\hline Antibody & $\begin{array}{l}\text { ACA } \\
\text { (n=63) }\end{array}$ & $\begin{array}{l}\text { Anti- } \\
\text { Scl70 } \\
(\mathrm{n}=31)\end{array}$ & $\begin{array}{l}\text { AntiU3- } \\
\text { RNP } \\
\text { (n=4) }\end{array}$ & $\begin{array}{l}\text { AntiU1- } \\
\text { RNP (n=3) }\end{array}$ & $\begin{array}{l}\text { Anti- } \\
\text { PMM/Scl } \\
\text { (n=2) }\end{array}$ & $\begin{array}{l}\text { Anti- } \\
\text { RNA pol } \\
3(n=1)\end{array}$ & $\begin{array}{l}\text { Anti- } \\
\text { Th/To } \\
\text { (n=1) }\end{array}$ \\
\hline $\begin{array}{l}\text { Onset age } \\
\text { mean+-SD } \\
\text { (years) }\end{array}$ & $57.1 \pm 12.9$ & $52 \pm 20.3$ & $49.4 \pm 9.2$ & $48.7 \pm 10.4$ & $42.5 \pm 14.8$ & 46 & 26 \\
\hline Fernale & $98.4 \%$ & $90.3 \%$ & $75 \%$ & $66.7 \%$ & $50 \%$ & $0 \%$ & $100 \%$ \\
\hline IcSSc & $85.7 \%$ & $38.7 \%$ & $25 \%$ & $0 \%$ & $50 \%$ & $100 \%$ & $100 \%$ \\
\hline dcSSc & $0 \%$ & $54.8 \%$ & $75 \%$ & $33.3 \%$ & $0 \%$ & $0 \%$ & $0 \%$ \\
\hline Overlap & $1.6 \%$ & $6.4 \%$ & $0 \%$ & $66.7 \%$ & $50 \%$ & $0 \%$ & $0 \%$ \\
\hline $\begin{array}{l}\text { Vascular } \\
\text { involvement }\end{array}$ & $79.4 \%$ & $51.6 \%$ & $25 \%$ & $33.3 \%$ & $0 \%$ & $0 \%$ & $100 \%$ \\
\hline PAH & $6.3 \%$ & $3.2 \%$ & $0 \%$ & $0 \%$ & $0 \%$ & $0 \%$ & $0 \%$ \\
\hline $\begin{array}{l}\text { Lung } \\
\text { involvement }\end{array}$ & $1.6 \%$ & $45.2 \%$ & $25 \%$ & $0 \%$ & $50 \%$ & $0 \%$ & $0 \%$ \\
\hline $\begin{array}{l}\text { Cardiac } \\
\text { involvement }\end{array}$ & $0 \%$ & $3.2 \%$ & $0 \%$ & $0 \%$ & $0 \%$ & $0 \%$ & $0 \%$ \\
\hline $\begin{array}{l}\text { Oelophageal } \\
\text { involvement }\end{array}$ & $57.1 \%$ & $45.2 \%$ & $0 \%$ & $0 \%$ & $0 \%$ & $100 \%$ & 0 \\
\hline $\begin{array}{l}\text { Faecal } \\
\text { incontinence }\end{array}$ & $4.8 \%$ & $0 \%$ & $25 \%$ & $0 \%$ & $0 \%$ & $0 \%$ & $0 \%$ \\
\hline $\begin{array}{l}\text { Renal } \\
\text { involvement }\end{array}$ & $0 \%$ & $0 \%$ & $25 \%$ & $0 \%$ & $0 \%$ & $0 \%$ & $0 \%$ \\
\hline $\begin{array}{l}\text { MS } \\
\text { involvement }\end{array}$ & $12.7 \%$ & $12.9 \%$ & $25 \%$ & $66.7 \%$ & $50 \%$ & $0 \%$ & $0 \%$ \\
\hline
\end{tabular}

Legend: ACA - anticentromere antibody; anti-Scl70 - antitopoisomerase I; IcSSC - limited cutaneous systemic sclerosis; dcSSc - diffuse cutaneous systemic sclerosis; $\mathrm{PAH}$ - pulmonary arterial hypertension; GI - gastro-intestinal; MS - muscleskeletal 
Anti-U1RNP was associated with muscle-skeletal manifestations (OR: 10.7 95\% Cl 0.92-20.44) and with overlap syndromes (OR: 15.2 95\% Cl 4.7-29.1). Pts with anti-Th/To and anti-RNA-polymerase III had IcSSc subtype. Vascular manifestations, oesophageal involvement and calcinosis cutis were the main manifestations, respectively. Table 1 shows detailed clinical manifestations and antibody profile.

Conclusions: In our cohort, ACA and anti-Scl70 were the commonest antibodies and were associated with IcSSC and dsSSc phenotype, respectively. ACA positivity conferred a higher risk of vascular disease and had a protective effect for ILD, while anti-Scl70 was associated with ILD.

Pts with anti-U1 RNP and anti-PM/Scl had mainly muscle-skeletal manifestations. This study confirms an association between immunological profile and clinical manifestations, reinforcing the importance of antibody profile and raising awareness for possible disease complications. Larger national studies would be desirable, specially for a better understanding of major organ involvement associated with least common antibodies.

Disclosure of Interest: None declared

DOI: 10.1136/annrheumdis-2018-eular.2941

\section{AB0728 NAILFOLD CAPILLAROSCOPY IN SYSTEMIC SCLEROSIS - SIX YEARS IN REVIEW}

A.C. Duarte, A. Cordeiro, M.J. Santos. Rheumatology, Hospital Garcia de Orta, Almada, Portugal

Background: Microvascular dysfunction is a dynamic process that is crucial in systemic sclerosis'(SSc) pathogenesis. Nailfold capillaroscopy(NCP) is a rapid, non-invasive exam that illustrates the early capillary changes in SSc and monitor their evolution. It is extremely useful in clinical practice and has been recognised in 2013 ACR/EULAR classification criteria for SSc.

Objectives: Evaluate the prevalence and evolution of NCP scleroderma pattern in SSc patients and analyse possible associations with disease-phenotype.

Methods: NCP of SSc patients followed in our centre were reviewed; clinical and demographic features were collected. A descriptive analysis was performed and nonparametric tests compared patients with and without SSc pattern

Results: In total, 70 out of 117 SSc patients had at least 1 NCP available during the last 6 years. Most of these patients(62.9\%) had limited cutaneous SSc, $21.4 \%$ diffuse cutaneous SSc, $11.4 \%$ very early diagnosis SSc and $4.3 \%$ overlap syndromes; mean disease duration was $10.7 \pm 9.6$ years

At the moment of the first NCP, 46 patients(39.4\%) had a scleroderma pattern, 12 $(10.3 \%)$ had non-specific(NS) NCP abnormalities and 12 had a normal NCP. During the 6 years follow-up, NCP changed in 5 patients as illustrated in figure 1 . However, none had concomitant development/worsening of other clinical manifestations.

At the end of the follow-up, $49(70 \%)$ patients had a NCP scleroderma pattern. Early pattern was present in $13(26.5 \%)$ patients, active pattern in $21(42.9 \%)$ active/late pattern in $3(6.1 \%)$ and late pattern in 12 (24.5\%).

When comparing patients with and without scleroderma specific patterns (table 1 ), the presence of scleroderma pattern was associated with the presence of current/previous digital ulcers(OR $1.4995 \% \mathrm{Cl} 1.17-1.92)$. However, this difference was not confirmed between the different scleroderma patterns.

Regarding, major organ involvement, although there were no statistical differences between both groups, patients with scleroderma pattern had a higher prevalence of oesophageal involvement.

Abstract AB0728 - Table 1. Comparison between patients with and without scleroderma pattern

\begin{tabular}{|c|c|c|c|c|c|c|c|}
\hline & \multicolumn{2}{|c|}{ Non-scleroderma } & \multicolumn{4}{|c|}{ Scleroderma } & \multirow[t]{2}{*}{$p$} \\
\hline NCP paattern & $\begin{array}{c}\text { Normal } \\
(n=10)\end{array}$ & $\begin{array}{c}\text { Non-specific } \\
\text { abnormalities } \\
(n=11)\end{array}$ & $\begin{array}{l}\text { Early } \\
(\mathrm{n}=13)\end{array}$ & $\begin{array}{l}\text { Active } \\
(\mathrm{n}=21)\end{array}$ & $\begin{array}{l}\text { Active/ } \\
\text { Late } \\
(n=3)\end{array}$ & $\begin{array}{l}\text { Late } \\
(n=12)\end{array}$ & \\
\hline Female & $100 \%$ & $72.7 \%$ & $100 \%$ & $85.7 \%$ & $66.7 \%$ & $91.7 \%$ & 0.623 \\
\hline Age & $\begin{array}{c}55.3 \\
\pm 16.2\end{array}$ & $66.7 \pm 5.7$ & $\begin{array}{c}58.2 \\
\pm 20.7\end{array}$ & $\begin{array}{c}53.8 \\
\pm 15.8\end{array}$ & $\begin{array}{c}44.9 \\
\pm 18.2\end{array}$ & $\begin{array}{r}64.9 \\
\pm 9.3\end{array}$ & 0.219 \\
\hline $\begin{array}{l}\text { Disease duration } \\
\text { (years) }\end{array}$ & $9.4 \pm 6.6$ & $8.3 \pm 4.4$ & $7.6 \pm 6$ & $\begin{array}{l}10.2 \\
\pm 7.1\end{array}$ & $\begin{array}{c}4.2 \\
\pm 0.6\end{array}$ & $\begin{array}{r}19.6 \\
\pm 16.6\end{array}$ & 0.947 \\
\hline $\begin{array}{l}\text { Diffuse cutaneous } \\
\text { dissease }\end{array}$ & $10 \%$ & $27.3 \%$ & $7.7 \%$ & $14.3 \%$ & $33.3 \%$ & $33.3 \%$ & 0.689 \\
\hline Digital ulcers & $10 \%$ & $0 \%$ & $30.8 \%$ & $28.6 \%$ & $33.3 \%$ & $33.3 \%$ & 0.021 \\
\hline $\begin{array}{l}\text { Pulmonary arterial } \\
\text { hypertension }\end{array}$ & $0 \%$ & $0 \%$ & $0 \%$ & $0 \%$ & $0 \%$ & $0 \%$ & NA \\
\hline $\begin{array}{l}\text { Interstitial lung } \\
\text { disease }\end{array}$ & $10 \%$ & $18.2 \%$ & $7.7 \%$ & $9.5 \%$ & $33.3 \%$ & $25 \%$ & 0.948 \\
\hline $\begin{array}{l}\text { Oesophageal } \\
\text { involvement }\end{array}$ & $40 \%$ & $45.4 \%$ & $46.2 \%$ & $71.4 \%$ & $66.7 \%$ & $50 \%$ & 0.148 \\
\hline Anticentromere + & $50 \%$ & $45.4 \%$ & $69.2 \%$ & $57.1 \%$ & $0 \%$ & $58.3 \%$ & 0.557 \\
\hline $\begin{array}{l}\text { Antitopoisomerase } \\
1+\end{array}$ & $20 \%$ & $27.3 \%$ & $15.4 \%$ & $19 \%$ & $33.3 \%$ & $33.3 \%$ & 0.971 \\
\hline
\end{tabular}

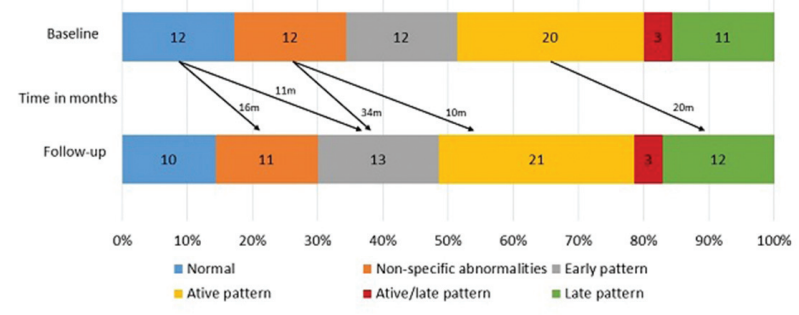

Abstract AB0728 - Figure 1. Progression of nailfold capillaroscopy alterations during follow-up

Conclusions: This study demonstrates how NCP can illustrate the dynamic vascular damage in SSc. In our data, a NCP scleroderma pattern was significantly associated with a higher number of digital ulcers and these patients had a higher percentage of oesophageal involvement.

In daily clinical practice, NCP is useful not only for corroborating SSc diagnosis, but also for monitoring endothelial injury and potential macrovascular/systemic damage. Although our sample is too small to demonstrate possible associations between specific NCP alterations and internal organ involvement, some studies have already identify NCP patterns as predictive factors for organ damage.

Disclosure of Interest: None declared

DOI: 10.1136/annrheumdis-2018-eular.3357

\section{AB0729 QUALITY OF LIFE ASSESSMENT IN SYSTEMIC SCLEROSISPATIENTS TREATED WITH AUTOLOGOUS STEM CELL TRANSPLANTATION: A LONGITUDINAL STUDY}

A.L.C. Guimaraes ${ }^{1}$, K. Costa-Pereira ${ }^{2}$, J.B. Elias ${ }^{2}$, D.A. Moraes ${ }^{2}$, E.A. OliveiraCardoso $^{1}$, J.T. Garcia ${ }^{1}$, M.C. Oliveira ${ }^{3}$, V. Leopoldo ${ }^{3}$, A.F. Zombrilli ${ }^{3}$, T.M. Costa ${ }^{2}$, M. Vasconcelos ${ }^{2}$, M.C. Oliveira ${ }^{2}{ }^{1}$ Ribeirao Preto School of Philosophy, Sciences and Literature; ${ }^{2}$ Division of Clinical Immunology, Ribeirao Preto Medical School; ${ }^{3}$ Ribeirao Preto School of Nursing, University of Sao Paulo, Ribeirao Preto, Brazil

Background: Autologous Hematopoietic Stem Cell Transplantation (AHSCT) has been explored as a therapeutic option for patients with systemic sclerosis (SSc) that do not respond to conventional treatment.

Objectives: To investigate changes in quality of life of severe and rapidly progressive SSc patients treated with AHSCT.

Methods: This is a longitudinal and comparative study. Patients were evaluated before $(n=27)$, and at $6(n=27)$ and 12 months $(n=21)$ after AHSCT. The Generic Questionnaire for Evaluation of Quality of Life Medical Outcomes Study 36 Item Short-Form Health Survey (SF-36) was applied individually, face-to-face, under patient written consent. This questionnaire evaluates eight domains: physical functioning (PF), role-physical (RP), bodily pain (BP), general health $(\mathrm{GH})$, social functioning (SF), vitality (VT), role-emotional (RE) and mental health (MH). Results were transformed into a 0-100 scale, where zero corresponds to a worse health condition and 100 to the best possible score, and submitted to statistical analysis. Significance was defined as $\mathrm{p}<0.05$.

Results: Most participants were females $(n=24)$, with mean age of 33 years (standard deviation, $\mathrm{SD}=10.33$ ) and mean time from diagnosis of 34.4 months $(\mathrm{SD}=34.89)$. Before $\mathrm{AHSCT}$, the mostly impaired aspects were: $\mathrm{PF}$ (mean $=8.33$, $\mathrm{SD}=18.34$ ), and RP (mean=38.52, $\mathrm{SD}=21.56)$, while $\mathrm{MH}$ (mean=61.63, $\mathrm{SD}=15.46$ ) and $\mathrm{SF}$ (mean=56.87, SD=27.17) were mostly preserved. At 6 and 12 months post-AHSCT, there was significant improvement of the SF-36 scores in the following domains: $P F(6$ months, $p<0.01,12$ months, $p<0.01)$; RP ( 6 months, $p<0.01,12$ months, $p<0.01)$; BP ( 6 months, $p<0.01,12$ months, $p<0.01)$; GH (6 months, $p<0.01,12$ months, $p=0.02)$; VT ( 6 months, $p<0.01,12$ months, $p<0.01$ ) $\mathrm{MH}$ (6 months, $p<0.01,12$ months, $p<0.01)$. The SF domain showed significant increase only at 12 months $(p=0.02)$. The only domain in which there was no significant change was RE.

Conclusions: Increases in the physical components of quality of life are more evident in the initial periods that follow AHSCT, while improvements in mental state, which are also associated with social aspects, are detected on longer follow-up. These data reinforce the relevance of AHSCT upon patient quality of life, signalling the importance of psychotherapeutic evaluations and follow-up.

Disclosure of Interest: None declared

DOI: 10.1136/annrheumdis-2018-eular.6811 